EDITORIAL

\title{
El idioma Guaraní en la Medicina
}

The Guaraní language in Medicine

Julia Irene Segovia Silva ${ }^{1}$

${ }^{1}$ Centro de Desarrollo Personal del Paraguay. Asunción, Paraguay

En el artículo Nivel de conocimiento sobre terminologías médicas en Guaraní de los profesionales de salud del Hospital Regional de Coronel Oviedo de Cabañas BM y colaboradores pone de manifiesto un déficit en la comunicación entre médicos y pacientes ${ }^{(1)}$.

El uso de las lenguas maternas en el marco de un enfoque plurilingüe es un componente esencial de la educación de calidad, que es la base para empoderar a las mujeres y a los hombres a sus sociedades, según la UNESCO en su declaración acerca de la importancia de las lenguas maternas ${ }^{(2)}$.

Ante esta afirmación, es digno destacar la gran importancia de la utilización del idioma Guaraní en los procesos de formación de los profesionales de la salud y en su ejercicio profesional. En el Paraguay, una inmensa cantidad de pacientes que acude a los hospitales públicos y privados se expresa preferentemente en guaraní, en el idioma de su confianza y de sus afectos. Esta situación obliga a reconocer el gran valor del conocimiento y la utilización de la lengua materna en los procesos de atención a los pacientes, a fin de que los mismos adquieran seguridad y comprendan mejor las orientaciones proporcionadas por el médico.

La enseñanza del idioma guaraní en la carrera de Medicina, como una asignatura más del currículum, no permite adquirir las habilidades comunicativas básicas, necesarias para que el futuro médico pueda comunicarse con fluidez y comprenda lo que sus pacientes, guaraní 
parlantes, expresan al momento de ser atendidos en los hospitales y puestos de salud. Es preocupante la situación real del idioma en nuestra sociedad académica puesto que existen carreras universitarias que ni siquiera como asignatura lo contemplan en sus planes curriculares. Ante esta situación es ideal que la enseñanza del Guaraní sea transversal y que no se la conciba como una lengua enseñada simplemente, sino como un idioma de práctica, que permita que todo el currículum esté impregnado de esta cultura y lenguaje.

No basta con enseñar a leer y escribir en guaraní. En Medicina es fundamental entender la cultura del paciente y comprender sus circunstancias a través de las facilidades de relación que permite la utilización del idioma materno en la comprensión de sus ideas y la actitud empática de quienes cumplen con la profesión de médicos.

A través de la utilización del idioma Guaraní se instala una cultura de confraternidad, de solidaridad y de compromiso con la patria. El empleo de esta lengua al momento de ejercer la profesión de médico marca una gran diferencia entre quienes ejercen la Medicina con la ciencia y quienes la ejercen con la sabia conciencia de que no basta con solo aplicar los principios científicos, sino que además es necesario y urgente entrar en el mundo del paciente, auscultar su cultura y comprender su realidad por medio de una comunicación abierta, sencilla y oportuna en su lengua materna.

Si el médico es capaz de comunicarse en Guaraní estará en un sitial de privilegio en cuanto al respeto y la consideración de su paciente, pues una persona que utiliza el idioma, no solo lo habla sino además piensa, siente y se proyecta de acuerdo a los códigos, a los usos y costumbres que propone la cultura y que son transmitidos y preservados a través de la utilización del lenguaje autóctono en la comunicación cotidiana. 
“Una lengua no es sólo un código de comunicación, es también una manera de conocer y categorizar la realidad, los conocimientos sobre la naturaleza, las relaciones sociales y las emociones"

\section{MBO'EHÁRA JULIA IRENE SEGOVIA SILVA}

EDITORIALISTA INVITADA

Correo Electrónico: jirenesegovia@gmail.com

\section{REFERENCIAS}

1. Cabañas BM, Escobar-Salinas JS, Ríos González CM, Frutos Chamorro TL, Invernizzi Prats JM. Nivel de conocimiento sobre terminologías médicas en Guaraní de los profesionales de salud del Hospital Regional de Coronel Oviedo. Rev Del Nacional (Itauguá) 2017;9(1):4-16

2. d'Emilio AL, Ruiz E. Lenguas y Educación, una mirada desde UNICEF. 2008.

Disponible

en:

cendoc.docip.org/collect/cendocdo/index/assoc/HASHfd56/ecf210ff. dir/PF08 anna108.pdf 